Research Article

\title{
Dispersion of transposable elements and multigene families: Microstructural variation in Characidium (Characiformes: Crenuchidae) genomes
}

\author{
Marcela Baer Pucci $^{1}$, Viviane Nogaroto ${ }^{2}$, Orlando Moreira-Filho ${ }^{1}$ and Marcelo Ricardo Vicari ${ }^{2}$ iD \\ ${ }^{1}$ Departamento de Genética e Evolução, Universidade Federal de São Carlos, São Carlos, SP, Brazil. \\ ${ }^{2}$ Departamento de Biologia Estrutural, Molecular e Genética, Universidade Estadual de Ponta Grossa \\ Ponta Grossa, PR, Brazil.
}

\begin{abstract}
Eukaryotic genomes consist of several repetitive DNAs, including dispersed DNA sequences that move between chromosome sites, tandem repeats of DNA sequences, and multigene families. In this study, repeated sequences isolated from the genome of Characidium gomesi were analyzed and mapped to chromosomes in Characidium zebra and specimens from two populations of $C$. gomesi. The sequences were transposable elements (TEs) named retroelement of Xiphophorus (Rex); multigene families of U2 small nuclear RNA (U2 snRNA); and histones $\mathrm{H} 1, \mathrm{H} 3$, and H4. Sequence analyses revealed that U2 snRNA contains a major portion corresponding to the Tx1-type non-LTR retrotransposon Keno, the preferential insertion sites of which are U2 snRNA sequences. All histone sequences were found to be associated with TEs. In situ localization revealed that these DNA sequences are dispersed throughout the autosomes of the species, but they are not involved in differentiation of the specific region of the $\mathrm{W}$ sex chromosome in $C$. gomesi. We discuss mechanisms of TE invasion into multigene families that lead to microstructural variation in Characidium genomes.
\end{abstract}

Keywords: Mobile DNA, histones, karyotype evolution, snRNA, WZ/ZZ.

Received: April 25, 2017; Accepted: November 29, 2017.

\section{Introduction}

The genomes of all studied eukaryotic species primarily consist of repetitive sequences that are dispersed or found in tandem (Sumner, 2003). Repetitive sequences were identified in fragile sites and evolutionary break point regions, promoting non-B DNA conformations and double-strand breaks, which are involved in chromosomal rearrangements (Eichler and Sankoff, 2003; Szamalek, 2005; Wells, 2007; Barros et al., 2017). Repetitive sequences are also responsible for a significant portion of the karyotype variations observed in many groups of organisms (Kidwell, 2002).

Dispersed DNA sequences can move between chromosome sites, with this movement occurring in the presence or absence of RNA as a transposition intermediate (Tollis and Boissinot, 2012). These mobile segments are called transposable elements (TEs) and are classified as retrotransposons (class I elements, RNA intermediates of the transposition process) or transposons (class II elements, DNA intermediates of the transposition process) (Wicker $e t$ al., 2007). These mobile elements can drive genetic and

Send correspondence to Marcelo Ricardo Vicari. Departamento de Biologia Estrutural, Molecular e Genética, Universidade Estadual de Ponta Grossa, Av. Carlos Cavalcanti, 4748, 84030-900 Ponta Grossa, PR, Brazil. E-mail: vicarimr@pq.cnpq.br genomic evolution and influence eukaryotic gene regulatory systems (Feschotte, 2008). In addition to consisting of dispersed DNA sequences, eukaryotic genomes are also enriched in tandem repeats of DNA sequences (Hardman, 1986) and groups of repeated and linked genes located at the same chromosomal region, shaping clustered but not tandemly repeated genes such as multigene families (Hentschel and Birnstiel, 1981; Heintz et al., 1991).

A multigene family is described as a group of genes with similar functions and sequences that originate from a common ancestral gene (Nei and Rooney, 2005). The U2 small nuclear RNA (U2 snRNA) sequence represents a multigene family of snRNA that control premessenger RNA intron splicing (Nei and Rooney, 2005). Histone genes do not have introns, and they comprise a multigene family in which the five genes are in the same order but separated by spacer DNA (Hentschel and Birnstiel, 1981). In the rainbow trout (Salmo gairdneri), the histones are present in the order of $H 4-H 2 B-H 1-H 2 A-H 3$, and they are transcribed from the same strand (Connor et al., 1984).

Concerning genome diversification, fish represent an important group for studies of genetic variability. The genus Characidium (Characiformes: Crenuchidae) presents a diversified karyotype microstructure despite its conserved karyotype macrostructure and prevalent diploid number 
(2n) of 50 (Centofante et al., 2001, 2003; Vicari et al., 2008; Pazian et al., 2013; Scacchetti et al., 2015a; Pucci et al., 2016; Serrano et al., 2017). The Characidium species studied to date exhibited differences mainly in the number of ribosomal DNA sites and sex chromosomes (Pansonato-Alves et al., 2010, 2011, 2014; Pucci et al., 2014; Scacchetti et al., 2015a, Utsunomia et al., 2017), as well as an interesting dynamic of repetitive DNAs (Scacchetti et al., 2015b; Pucci et al., 2016).

The primary goal of this study was to perform sequence analyses and chromosome mapping of some repeated sequences isolated from the genome of $C$. gomesi. Retroelement of Xiphophorus (Rex) TEs were mapped to chromosomes to elucidate their possible involvement in Characidium karyotype evolution and diversification. The multigene families of $U 2 \operatorname{snRNA}$ and histones $H 1, H 3$, and $H 4$ were also investigated through chromosome mapping and sequence analyses. Our study revealed associations between TEs and the multigene families. The obtained results will improve our understanding of the evolution and diversification of Characidium genomes.

\section{Materials and Methods}

\section{Sampling and chromosome preparation}

Individuals of the following species were collected at the indicated locations: C. zebra (15 specimens; Paiol Grande Stream, São Bento do Sapucaí, SP) and C. gomesi (nine specimens; Paiol Grande Stream, São Bento do Sapucaí, SP/five specimens; São João River, Carambeí, PR). Chromosomes for analyses were obtained using the 'airdrying' procedure (Bertollo et al., 1978). The analyzed specimens were then deposited in the following ichthyology museums: Núcleo de Pesquisas em Limnologia, Ictiologia e Aquicultura (Nupelia), Universidade Estadual de Maringá, and Museu Nacional, Rio de Janeiro, Brazil, voucher numbers (NUP 14577-14580; MNRJ 29183). The processing was performed in accordance with the Ethical Committee on Animal Use (CEUA 29/2016) of the Universidade Estadual de Ponta Grossa and current Brazilian legislation. Chromosome preparations were subjected to conventional Giemsa staining to determine $2 \mathrm{n}$ and the chromosome formula.

\section{Sequence isolation}

The analyzed sequences were synthesized by polymerase chain reaction (PCR) using genomic DNA from $C$. gomesi (São João River population), and the reaction mixtures consisted of 100-200 ng of genomic DNA, 0.04-0.2 $\mu \mathrm{M}$ primers, $0.04-0.16 \mathrm{mM}$ dNTPs, 1 U of Taq DNA Polymerase (Invitrogen, Waltham, MA, USA), and $1.5 \mathrm{mM}$ $\mathrm{MgCl}_{2}$ in a 1 reaction buffer $(200 \mathrm{mM}$ Tris, $\mathrm{pH} 8.4,500$ $\mathrm{mM} \mathrm{KCl}$ ). The specific PCR mixtures and primers sequences are summarized in Table S1. The PCR conditions were as follows: (i) $\operatorname{Rex} 1$ and $\operatorname{Rex} 3$ probes: $95^{\circ} \mathrm{C}$ for $5 \mathrm{~min}$,
35 cycles of $95^{\circ} \mathrm{C}$ for $1 \mathrm{~min}, 55^{\circ} \mathrm{C}$ for $40 \mathrm{~s}$ and $72{ }^{\circ} \mathrm{C}$ for 2 min, and a final extension at $72^{\circ} \mathrm{C}$ for $5 \mathrm{~min}$; (ii) $U 2 s n R N A$ probe: $95{ }^{\circ} \mathrm{C}$ for $45 \mathrm{~s}, 30$ cycles of $95^{\circ} \mathrm{C}$ for $45 \mathrm{~s}, 52^{\circ} \mathrm{C}$ for $45 \mathrm{~s}$ and $72{ }^{\circ} \mathrm{C}$ for $80 \mathrm{~s}$, and a final extension at $72{ }^{\circ} \mathrm{C}$ for 7 min; and (iii) histones $\mathrm{H} 1, \mathrm{H} 3$, and $\mathrm{H} 4: 95^{\circ} \mathrm{C}$ for $5 \mathrm{~min}, 30$ cycles of $95^{\circ} \mathrm{C}$ for $30 \mathrm{~s}, 52^{\circ} \mathrm{C}$ for $45 \mathrm{~s}$ and $72{ }^{\circ} \mathrm{C}$ for $80 \mathrm{~s}$, and a final extension at $72{ }^{\circ} \mathrm{C}$ for $7 \mathrm{~min}$.

\section{TEs and multigene family sequences: Sequencing and analyses}

After the amplification reactions, the PCR products were purified using the GenElute PCR Clean-Up Kit (Sigma Aldrich, St Louis, MO, USA). Rex1 and Rex3 sequences were cloned using pGEM®-T Easy Vector Systems (Promega, Madison, WI, USA). The obtained clones were sequenced using an ABI-PRISM Genetic Analyzer (Applied Biosystems, Carlsbad, CA, USA). The sequences were edited and analyzed using Geneious 7.1.3 software (Kearse et al., 2012), and their identities were confirmed using the CENSOR tool for repeated sequences (Girinst) (Kohany et al., 2006) and BLASTn (NCBI). Finally, the sequences were deposited in GenBank (Table S2).

\section{Probe preparation}

The sequences of Rex3, U2 snRNA, and histones H1 and $\mathrm{H} 4$ were labeled with digoxigenin via nick translation using DIG-Nick Translation Mix (Roche Applied Science, Penzberg, Germany), and those of Rex1 and H3 were biotinylated using Biotin-Nick Translation Mix (Roche Applied Science). A C. gomesi $\mathrm{W}$-specific chromosome probe was constructed as described by Machado et al. (2011), labeled with digoxigenin 11-dUTP (Roche Applied Science), and used in fluorescence in situ hybridization (FISH) to identify sex chromosomes in the karyotypes.

\section{$\mathrm{FISH}$}

Chromosome spreads were subjected to FISH using the constructed probes. FISH was performed under a high stringency of approximately $76 \%(2.5 \mathrm{ng} / \mu \mathrm{L}$ of each probe, $50 \%$ formamide, $2 \mathrm{SSC}, 10 \%$ dextran sulfate, $\mathrm{pH} 7.0-7.2$, $37^{\circ} \mathrm{C}$ overnight) following the general procedure described by Pinkel et al. (1986). Signal detection was performed using an anti-streptavidin antibody conjugated to Alexa Fluor 488 (Molecular Probes, Eugene, OR, USA) and an antidigoxigenin antibody conjugated to rhodamine (Roche Applied Science). Chromosomes were counterstained with 4'6-diamidino-2-phenylindole $(0.2 \mu \mathrm{g} / \mathrm{mL})$ in Vectashield mounting medium (Vector Laboratories, Burlingame, CA, USA) and observed under an epifluorescence microscope.

\section{Karyotype analysis}

Approximately 20 metaphases were analyzed for each species, and karyotypes were determined from the highest-quality images. Chromosomes were classified as metacentric, submetacentric, subtelocentric, or acrocentric 
according to the arm ratio (Levan et al., 1964) and arranged by decreasing size in the karyotypes.

\section{Results}

\section{Analyses of partial sequences of TEs and multigene families}

The partial sequences of Rexl, Rex3, U2 snRNA, and the $\mathrm{H} 1, \mathrm{H} 3$, and $\mathrm{H} 4$ genes were isolated from the genomes of C. gomesi and C. zebra, and consensus sequence of each gene was constructed (Table S2). When analyzed using the CENSOR tool, the multigene family sequences displayed high proportions of retrotransposon sequences as follows: U2 snRNA contained the Tx1-type element called Keno-1_SSa (Figure 1a); H1 contained an internal portion (217 bp) of an ERV1-type endogenous retrovirus sequence (Figure 1b); H3 displayed an internal portion (52 bp) of the LTR retrotransposon Gypsy (Figure 1c), although chromosome mapping of this sequence only revealed the main $\mathrm{H} 3$ histone clusters with no evidence of dispersed clusters; and $\mathrm{H} 4$ contained an internal portion (37 bp) of the LTR retrotransposon Gypsy (Figure 1d).

\section{Cytogenetics of Characidium}

The studied species presented a $2 \mathrm{n}$ of 50 , and these chromosomes have been cytogenetically described by Machado et al. (2011) and Pucci et al. (2014). Karyotype formulae were organized as 32 metacentric +18 submetacentric, excluding females of $C$. gomesi (São João River population), which were organized as 31 metacentric +18 submetacentric +1 subtelocentric. The fundamental number of chromosome arms was 100 in all studied species/populations. No differentiated sex chromosomes were found in the C. zebra population. The C. gomesi $\mathrm{W}$-specific probe revealed sex chromosomes as metacentric pair 2 in C. gomesi from the Paiol Grande Stream population and metacentric $\mathrm{Z}$ position 2 and subtelocentric W in C. gomesi from the São João River population (Figure 2, Z and W chromosomes are highlighted in the box).

\section{Chromosome mapping of Rex1 and Rex3 on Characidium chromosomes}

The non-LTR retrotransposons $\operatorname{Rex} 1$ and $\operatorname{Rex} 3$ in $C$. zebra and $C$. gomesi were observed in a few chromosomes (Figure 2a-e). In C. zebra, Rexl displayed more prominent hybridization signals in metacentric pair 3 and submetacentric pairs 18 and 19 (Figure 2a). In C. gomesi from the Paiol Grande Stream population, Rex 1 exhibited strong signals in metacentric pairs 8 and 13 (Figure 2b). In C. gomesi from the São João River population, Rexl exhibited clear marks in metacentric pairs 4, 5, and 8 and submetacentric pair 19 (Figure 2c). However, Rexl did not display clear marks in the $\mathrm{Z}$ and $\mathrm{W}$ chromosomes either $C$. gomesi population (Figure $2 \mathrm{~b}-\mathrm{c}$ ). In C. zebra, Rex3 exhibited convincing hybridization signals in metacentric pairs 1,3 , and 8 and submetacentric pair 17 (Figure 2d). In C. gomesi from the São João River population, $\operatorname{Rex} 3$ displayed signals in metacentric pairs $1,3,4,6,7,8,14$, and 16 and submetacentric pairs 17, 22, and 25 (Figure 2e). Rex3 did not hy-

a)

GCTTCTCGGCCTTATGGCTAAGATCAAGTGTAGTATCTTTCTATCAGTTTATATCTGATACGTCCTCTATATGAGGACTACATAT Target site for Keno

TAAATTGATTTTAGAACTGGGAGACGGGAAAGGACTTGCTCCGCCCGCTCCACGCATCGACCTGGTATTGCAGTACCGCCGGGAA

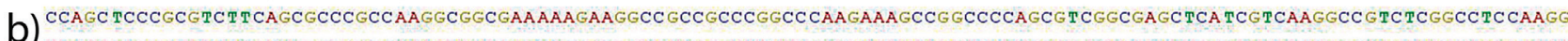
AGAGGAGCGGCGTTT TCTCGCCGCCC TGAAGAAAGCTCTGGCC GCCA G TGGCTACGAT GTGGAGAAGAACAACTCCCGCGTCAAGCTCGCCGTCAAGAGCC TGGTGACCAAA GGCAC GC TGG TGCAGACCAAG GGCACC GGC GC GTCTG T TC T T TCAAGC TCAACAAGAAGCAAACCGAGGC TGCAAAGAAGCCGGCCAAGAAAGT GGC TCCCAAAGC CAAGAAGGCGG TGGCC

AAGAAGCCCGTGGCTGCAAAGAAGCCCAAGAAGGTCGCCACCAAGAAG GCTGCGGTTGCCAAGAAGTCCC CCAAGAAGGCGAAGAAGCCCGCGCCGGCTAAGAAGGCCGCCAAGTCCC AAGAAGCCCGTGGCTGCAAAGAAGCCCAAGA.AGGTCGCCACCAAGAAG GCTGCGGTTGCCAAGAAGTCCC CCAAGAAGGCGAAGAAGCCCGCGCCGGCTAAGAAGGCCGCCAAGTCCC
ERV1-2FCa-I CGAAGAAGGCCAAGAA GCCCGCCGCTCCGAAGAAGGCGGCCAAGAGCCCCAAGAAGGCCAAGACCG TCAAGCCCAAAACA GCCAAGCCCAA GGCGGCGAAGGCCAAAAAGGCAGC ERV1-2FCa-I

C) GCCCGTAAGTCCACCGGTGGCAAAGCCCCGAGGAAGCAGCTGGCCACCAAGGCCGCTCGTAAGAGCGCCCCGGCCACCGGCGGAGTGAAGAAGCCTCACCGTTACAGGCCCG Gypsy-16_SB-I

GCACC GT GGCTCTGAGG GAGATCC GTCGTTACCAGAA GTCCACC GA GCT GCTGATCC GCAAGCTGCCT T TCCAGCGTC TGG TGCGTGAGATCGCTCAGGACTTCAAGACCGA CC TCC GC TTCCAGAGCTCCGCCGTCATGGCTCTGCA G GAGGCCAGCGAGGCATACCTGGTGGGTCTGTTCGAG GACACCAACCTGTGC GCCATCCACGCCAAGAGAGTCAC

d)

CAGGGGATCACCAAGCCGGCTATTCGCCGTCTGGCCCGCCGTGGCGGTGTCAAGCGTATCTCCGGTCTGATCTACGAGGAGACCCGCGGCGTGCTGAAAGTGTTCCTGGAGAACGTGATCAGGGACGCCGTCACTTACACCGAGCACGCCAAGAGAAAG ACCGTCACCGCCATGGA Gypsy-28C_DR-1

Figure 1 - Partial sequences of multigene families isolated from $C$. gomesi genome, with TE insertion. (a) Partial sequence of the $U 2$ snRNA gene (yellow), associated with its specific U2-target Keno TE (blue); histone partial sequences, with the internal portion of TEs; (b) H1 with retrotransposon ERV1 (yellow); (c) H3 with retrotransposon Gypsy (yellow); (d) H4 with retrotransposon Gypsy (yellow). 


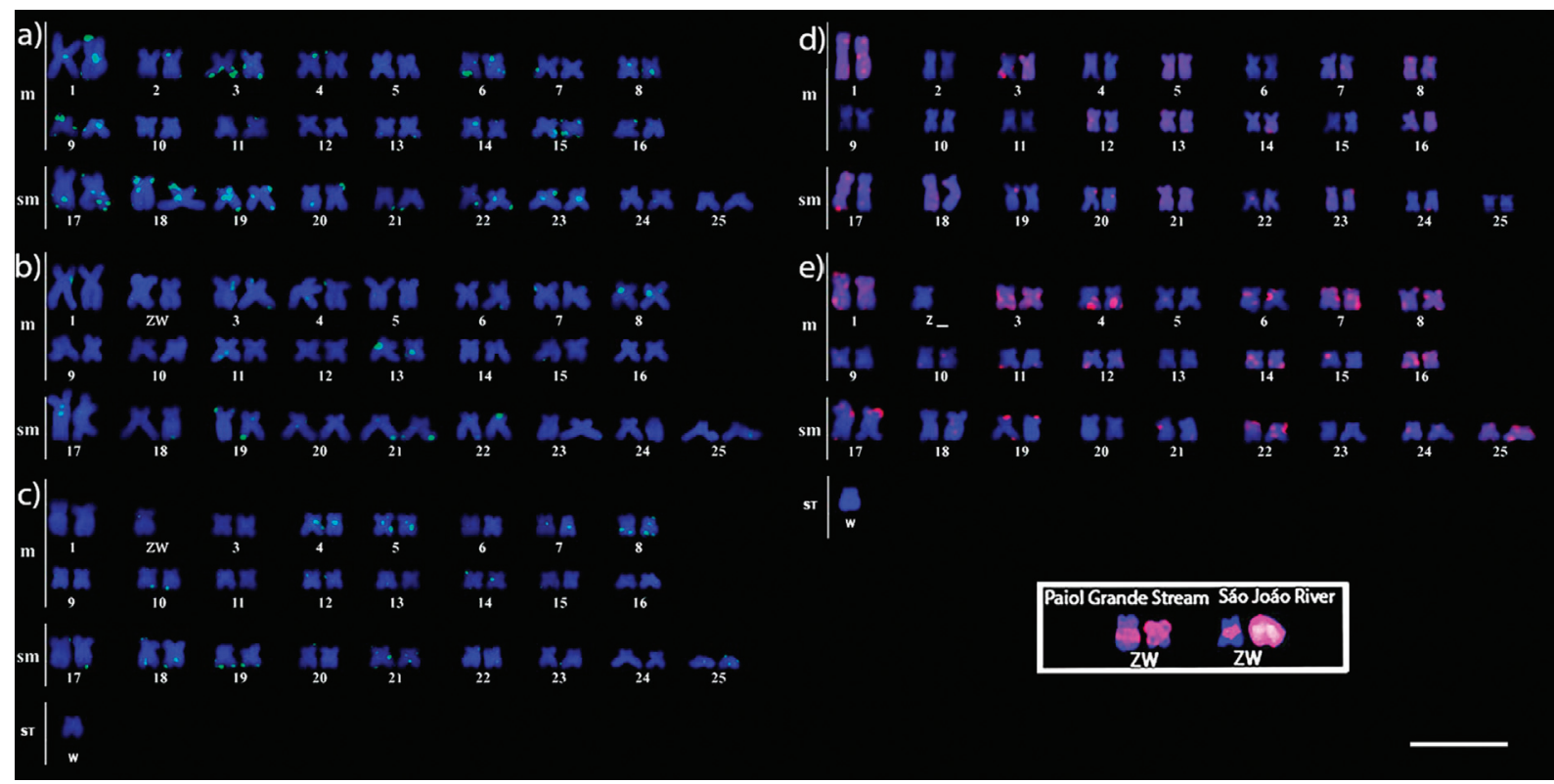

Figure 2 - Karyotypes of Characidium females subjected to fluorescence in situ hybridization (FISH) with TE probes. (a) C. zebra, (b) C. gomesi (PG), (c) C. gomesi (SJ); (d) C. zebra, (e) C. gomesi (SJ). The Rex3 probe did not show any hybridization signals in C. gomesi (PG) chromosomes (not shown). The $\mathrm{W}$ and $\mathrm{Z}$ sex chromosomes of $C$. gomesi females are highlighted in the box. PG, Paiol Grande Stream population; SJ, São João River population. Scale bar, $10 \mu \mathrm{m}$.

bridize with the $\mathrm{Z}$ and $\mathrm{W}$ chromosomes of $C$. gomesi from the São João River population (Figure 2e), nor did it exhibit hybridization signals in any chromosome of $C$. gomesi from the Paiol Grande Stream population (data not shown).

\section{Chromosome mapping of multigene families U2 snRNA and the $\mathrm{H} 1, \mathrm{H} 3$, and $\mathrm{H} 4$ genes on Characidium chromosomes}

The $U 2$ snRNA probe displayed a single cluster of hybridization signals in the pericentromeric region of metacentric pair 1 in all analyzed species, with no additional dispersed sites detected (Figure 3a-c).

The $\mathrm{H} 1$ histone gene probe displayed primary clusters of hybridization signals in the pericentromeric region and short arm of one chromosome of metacentric pair 10, whereas only one cluster was found in the pericentromeric region of the other chromosome in pair 10 of C. zebra (Figure 3d) and metacentric pair 10 of C. gomesi (Paiol Grande Stream population). An additional cluster was noted in pair 7 of $C$. gomesi from the Paiol Grande Stream population (Figure 3e) and metacentric pair 5 of C. gomesi from the São João River population (Figure $3 \mathrm{f}$ ). In addition, each species exhibited weak additional signals in several other autosomes (Figure 3d-f).

The H3 gene probe displayed primary clusters of hybridization signals in the pericentromeric region and short arm of one chromosome of metacentric pair 10 and one cluster in the pericentromeric region of the other chromosome in pair 10 of C. zebra (Figure 3g), the short arm of metacentric pair 10 of C. gomesi from the Paiol Grande Stream population (Figure $3 \mathrm{~h}$ ). One cluster was also found in the short arm of metacentric pair 5 of $C$. gomesi from the São João River population (Figure 3i).

The H4 gene probe revealed primary clusters of hybridization signals in the pericentromeric region and short arm of one chromosome in metacentric pair 10 and one cluster in the pericentromeric region of the other chromosome in pair 10 of C. zebra, as well as additional marks in metacentric pair 9 (Figure 3j) and the short arm of metacentric pair 10 of $C$. gomesi from the Paiol Grande Stream population (Figure $3 \mathrm{k}$ ) and a weak signal in metacentric pair 5 of C. gomesi from the São João River population (Figure 31). Marks were also noted in some autosomes of both populations of $C$. gomesi (Figure 3k-1).

\section{Discussion}

\section{Distribution of Rex1 and Rex3 on Characidium chromosomes}

Rex elements are non-LTR retrotransposons (Wicker et al., 2007) that are extensively distributed through fish genomes (Ozouf-Costaz et al., 2004; Ferreira et al., 2010; Borba et al., 2013; Schneider et al., 2013; Yano et al., 2014; Sene et al., 2015; Pinheiro et al., 2016), in addition to those of other species. Rex 1 and Rex3 are significant sequences in the organization and evolution of the genomes in most of the aforementioned species, as indicated by evident hybridization signals and prominent amounts of these sequences. In this analysis, $\operatorname{Rex} 1$ and $\operatorname{Rex} 3$ elements were dispersed in small clusters throughout the chromosomes, and they did not display significant chromosome reorganization between Characidium species. 


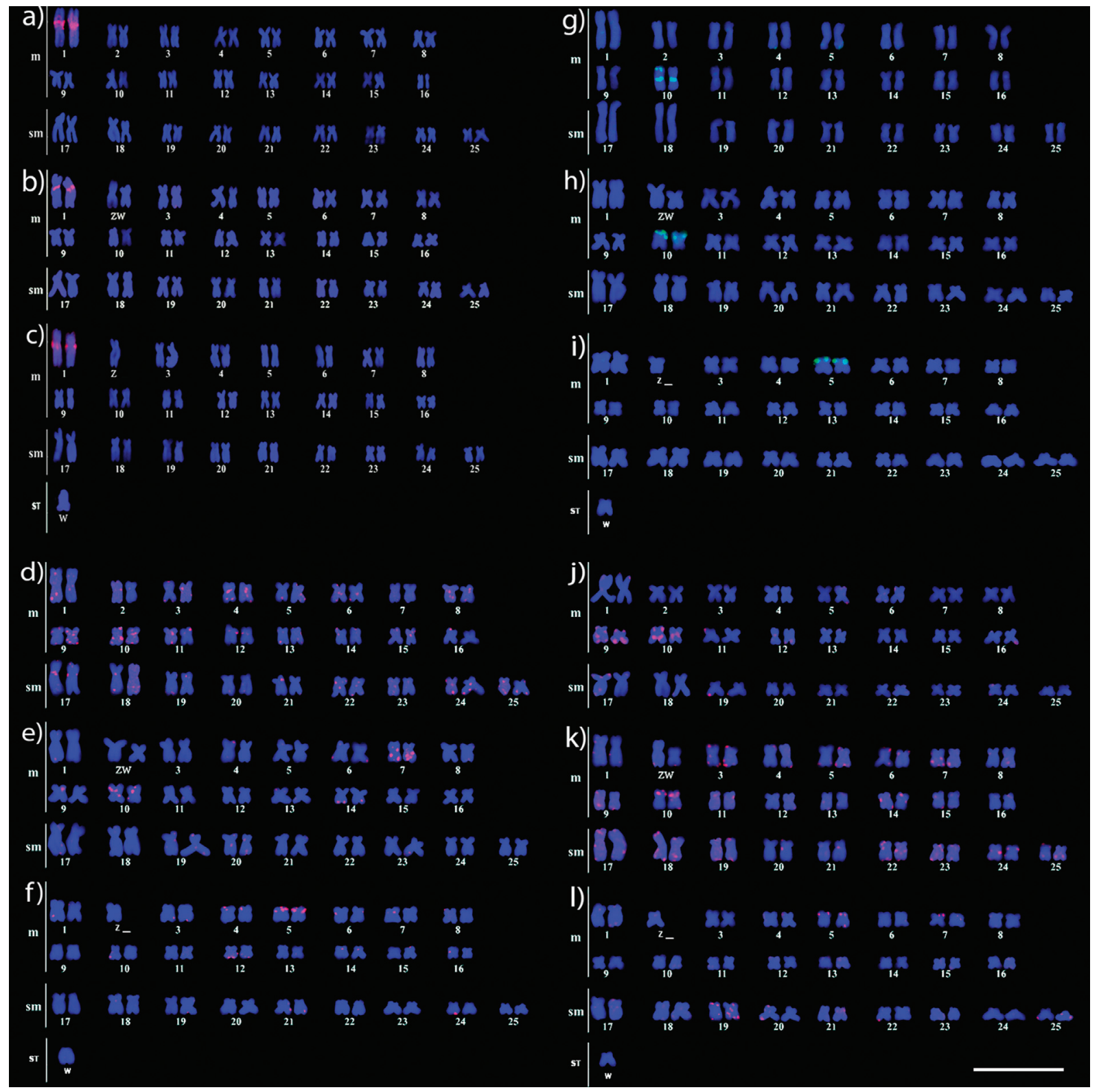

Figure 3 - Karyotypes of Characidium females subjected to fluorescence in situ hybridization (FISH) with multigene family probes. (a) C. zebra, (b) C. gomesi (PG), (c) C. gomesi (SJ); H1 (d) C. zebra, (e) C. gomesi (PG), (f) C. gomesi (SJ); (g) C. zebra, (h) C. gomesi (PG), (i) C. gomesi (SJ); (j) C. zebra, (k) C. gomesi (PG), (1) C. gomesi (SJ). PG, Paiol Grande Stream population; SJ, São João River population. Scale bar, $10 \mu \mathrm{m}$.

Concerning the distribution of $\operatorname{Rex} 1$ and $\operatorname{Rex} 3$ in the sex chromosomes, no hybridization sites were identified in the $\mathrm{Z}$ and $\mathrm{W}$ sex chromosomes of Characidium, whereas these elements are involved in sex chromosome evolution in other species. In particular, Rex3 was detected in the $\mathrm{Y}$ chromosome of Chionodraco hamatus (Ozouf-Costaz et al., 2004) and X chromosome of Eigenmannia (Sene et al., 2015); Rex 1 and $\operatorname{Rex} 3$ were found in the $\mathrm{W}$ chromosome of Leporinus (Borba et al., 2013); and Rex1, Rex3, and Rex6 were identified in the $\mathrm{Z}$ and $\mathrm{W}$ chromosomes of Triportheus (Yano et al., 2014). The Rex1 and Rex3 elements analyzed in the Characidium genome emerged in the ancestral species C. zebra. However, these elements did not exhibit high transposition rates, presenting only small clusters in some autosomes in all analyzed species. Moreover, the Rex3 element was not identified in the genome of $C$. gomesi from the Paiol Grande Stream population. Natural selection may minimize the transposition rate, promoting vertical inactivation (Lohe et al., 1995), which could be true for Rex elements in Characidium. Another possible explanation for the low transposition rate could be stochastic loss, in which the element is gradually removed from the genome, as observed for mariner-like elements in the Drosophila melanogaster species complex (Lohe et al., 1995) and probably for Rex3 in C. gomesi from the São João River population. 


\section{Multigene families and TE insertions}

Chromosome mapping of U2 SnRNA revealed localized clusters in the first metacentric pair in all studied species. In fact, the distribution pattern of $U 2 \operatorname{snRNA}$ is highly conserved for Characidium, as described by Scacchetti et al. (2015a), with only some exceptions such as Characidium sp. aff. C. vidali, Characidium sp. 1 (Scacchetti et al., 2015a), and C. alipioi (Serrano et al., 2017). U2 snRNA sequences appear to be conserved in other species, and co-localization and linkage between U2 genes and ribosomal sites has been reported (Cross and Rebordinos, 2005; Manchado et al., 2006; Úbeda-Manzanaro et al., 2010; Scacchetti et al., 2015a). Despite the presence of conserved clusters, sequence analyses of $U 2$ snRNA using the CENSOR tool revealed a major portion corresponding to the Tx1-type non-LTR retrotransposon Keno-1_SSa (Kohany et al., 2006). There are several sequence-specific families in the Tx element group, and Keno is specific for U2 snRNA (Kojima and Fujiwara, 2004). Insertion of the Keno element occurs at a specific site $37 \mathrm{nu}-$ cleotides downstream of U2 snRNA, and its insertion destroys the target (Kojima and Fujiwara, 2004). The Keno-1_SSa (Kohany et al., 2006) element found in the U2 snRNA sequence of Characidium is classified as KenoDr 1 because the specific 3' target sequence (TCTGTTCTTATCAGTTTAAT) localized 37 nucleotides downstream of U2 snRNA (Kojima and Fujiwara, 2004; Kojima and Jurka, 2015). Despite the TE insertion, the $U 2 \operatorname{snRNA}$ sequence did not exhibit additional clusters.

In situ localization for the $\mathrm{H} 1, \mathrm{H} 3$, and $\mathrm{H} 4$ sequences revealed primary clusters in metacentric pair 10 of C. zebra and $C$. gomesi from the Paiol Grande Stream population as well as metacentric pair 5 of $C$. gomesi from the São João River population. Additional hybridization signals for $\mathrm{H} 1$ and $\mathrm{H} 4$ were dispersed through the autosomes of the three populations, although not in the sex chromosomes. Chromosomal rearrangement and the absence of gene flow resulted in the differentiated karyotype of $C$. gomesi from the São João River population, which exhibited primary clusters of H1, H3, and H4 in metacentric pair 5 (translocation) and subtelocentric sex chromosome W (inversion). The sites of H3 were also localized to metacentric pair 10 in $C$. alipioi (Serrano et al., 2017), albeit in the long arms, pointing to the occurrence of rearrangements involving these chromosomes. Our analyses of the histone sequences also revealed LTR retrotransposon (Wicker et al., 2007) insertions of ERV1 (H1) and Gypsy (H3 and H4). The LTR retrotransposon Gypsy inserted in the $\mathrm{H} 3$ sequence was not involved in the spread of this sequence throughout the genome. Additional clusters of $\mathrm{H} 1$ and $\mathrm{H} 4$ are probably due to the involvement of TEs. Hence, the major force leading to chromosomal spread of the $\mathrm{H} 1$ and $\mathrm{H} 4$ sequences in the Characidium karyotypes were probably a consequence of hitchhiking by $\mathrm{H} 1$ and $\mathrm{H} 4$ with the mobile elementsmediated transposition events. However, these additional
$\mathrm{H} 1$ and $\mathrm{H} 4$ chromosomal marks could represent the Gypsy and ERV1 TE sequences alone without the histone genes adjacent to them.

Insertion of a TE inside or around a gene can alter its expression considerably, increasing or decreasing its expression when the insertion occurs in promoter regions, (Finnegan, 1989), or block gene expression by disrupting normal gene function (Chuong et al., 2016). However, it is difficult at present to determine the consequences of retrotransposon insertions in $U 2 s n R N A$ and the H3 gene of Characidium, as they are essential for cellular function.

Our results illustrated that the Characidium genome is dynamic concerning TEs. However, these TEs did not promote deep chromosomal reorganization of the Characidium karyotypes, nor were they involved in differentiation of the specific $\mathrm{W}$ sex chromosome region in $C$. gomesi. It is therefore desirable to identify and map other TEs in the Characidium genome to improve our understanding of karyotype and sex chromosome evolution in this fish genus. However, the results presented in this study will enable the detection of innumerous TE insertions/transpositions generating microstructural variation in Characidium genomes, including some TE invasions in gene families.

\section{Acknowledgments}

This study was supported by Fundação Araucária (Fundação Araucária de Apoio ao Desenvolvimento Científico e Tecnológico do Estado do Paraná), CNPq (Conselho Nacional de Desenvolvimento Científico e Tecnológico), CAPES (Coordenação de Aperfeiçoamento de Pessoal de Nível Superior) and SETI-PR (Secretaria de Estado da Ciência, Tecnologia e Ensino Superior do Estado do Paraná).

\section{References}

Barros AV, Wolski MAV, Nogaroto V, Almeida MC, MoreiraFilho O and Vicari MR (2017) Fragile sites, dysfunctional telomere and chromosome fusions: What is $5 \mathrm{~S}$ rDNA role? Gene 608:20-27.

Bertollo LAC, Takahashi CS and Moreira-Filho O (1978) Cytotaxonomic considerations on Hoplias lacerdae (Pisces, Erythrinidae). Braz J Genet 1:103-120.

Borba RS, Silva EL and Parise-Maltempi PP (2013) Chromosome mapping of retrotransposable elements Rex 1 and Rex3 in Leporinus Spix, 1829 species (Characiformes: Anostomidae) and its relationships among heterochromatic segments and W sex chromosome. Mob Genet Elements 3:e27460.

Centofante L, Bertollo LAC and Moreira-Filho O (2001) Comparative cytogenetics among sympatric species of Characidium (Pisces, Characiformes). Diversity analysis with the description of a ZW sex chromosome system and natural triploidy. Caryologia 54:253-260.

Centofante L, Bertollo LAC, Buckup PA and Moreira-Filho O (2003) Chromosomal divergence and maintenance of 
sympatric Characidium fish species (Crenuchidae, Characidiinae). Hereditas 138:213-218.

Chuong EB, Elde NC and Feschotte C (2016) Regulatory activities of transposable elements: From conflicts to benefits. Nat Rev Genet 18:71-86.

Connor W, Mezquita J, Winkfein RJ, States JC and Dixon GH (1984) Organization of the histone genes in the rainbow trout (Salmo gairdnerii). J Mol Evol 20:227-235.

Cross I and Rebordinos L (2005) 5S rDNA and U2 snRNA are linked in the genome of Crassostrea angulata and Crassostrea gigas oysters: does the $(\mathrm{CT})_{n}(\mathrm{GA})_{n}$ microsatellite stabilize this novel linkage of large tandem arrays? Genome 48:1116-1119.

Eichler EE and Sankoff D (2003) Structural dynamics of eukaryotic chromosome evolution. Science 301:793-797.

Ferreira DC, Oliveira C and Foresti F (2010) Chromosome mapping of retrotransposable elements Rexl and Rex3 in three fish species in the subfamily Hypoptopomatinae (Teleostei, Siluriformes, Loricariidae). Cytogenet Genome Res 132:64-70.

Feschotte C (2008) Transposable elements and the evolution of regulatory networks. Nat Rev Genet 9:397-405.

Finnegan DJ (1989) Eukaryotic transposable elements and genome evolution. Trends Genet 5:103-107.

Hardman N (1986) Structure and function of repetitive DNA in eukaryotes. Biochem J 234:1-11.

Heintz N, Zernik M and Roeder RG (1991) The structure of the human histone genes: Clustered but not tandemly repeated. Cell 24:661-668.

Hentschel CC and Birnstiel ML (1981) The organization and expression of histone gene families. Cell 25:301-313.

Kearse M, Moir R, Wilson A, Stones-Havas S, Cheung M, Sturrock S, Buxton S, Cooper A, Markowitz S, Duran C et al. (2012) Geneious Basic: An integrated and extendable desktop software platform for the organization and analysis of sequence data. Bioinformatics 28:1647-1649.

Kidwell MG (2002) Transposable elements and the evolution of genome size in eukaryotes. Genetica 115:49-63.

Kohany O, Gentles AJ, Hankus L and Jurka J (2006) Annotation, submission and screening of repetitive elements in Repbase: Repbase Submitter and Censor. BMC Bioinformatics 25:474.

Kojima KK and Fujiwara H (2004) Cross-genome screening of novel sequence-specific non-LTR retrotransposons: Various multicopy RNA genes and microsatellites are selected as targets. Mol Biol Evol 21:207-217.

Kojima KK and Jurka J (2015) Ancient origin of the U2 small nuclear RNA gene- targeting non-LTR retrotransposons Utopia. PLoS One 10:e0140084.

Levan A, Fredga K and Sandberg AA (1964) Nomenclature for centromeric position on chromosomes. Hereditas 52:201220.

Lohe AR, Moriyama EN, Lidholm DA and Hart DL (1995) Horizontal transmission, vertical inactivation, and stochastic loss of mariner-like transposable elements. Mol Biol Evol 12:62-72.

Machado TC, Pansonato-Alves JC, Pucci MB, Nogaroto V, Almeida MC, Oliveira C, Foresti F, Bertollo LA, MoreiraFilho O, Artoni RF et al. (2011) Chromosomal painting and ZW sex chromosomes differentiation in Characidium (Characiformes, Crenuchidae). BMC Genetics 12:65.
Manchado M, Zuasti E, Cross I, Merlo A, Infante C and Rebordinos L (2006) Molecular characterization and chromosomal mapping of the 5S rRNA gene in Solea senegalensis: A new linkage to the U1, U2, and U5 small nuclear RNA genes. Genome 49:79-86.

Nei M and Rooney AP (2005) Concerted and birth-and-death evolution of multigene families. Annu Rev Genet 39:121-152.

Ozouf-Costaz C, Brandt J, Körting C, Pisano E, Bonillo C, Coutanceau J-P and Volff J-N (2004) Genome dynamics and chromosomal localization of the non-LTR retrotransposons Rex 1 and Rex3 in Antarctic fish. Antarct Sci 16:51-57.

Pansonato-Alves JC, Paiva LRS, Oliveira C and Foresti F (2010) Interespecific chromosomal divergences in the genus Characidium (Teleostei: Characiformes: Crenuchidae). Neotrop Ichythyol 8:77-86.

Pansonato-Alves JC, Vicari MR, Oliveira C and Foresti F (2011) Chromosomal diversification in populations of Characidium cf. gomesi (Teleostei, Crenuchidae). J Fish Biol 78:183-194.

Pansonato-Alves JC, Serrano EA, Utsunomia R, Camacho JPM, Silva GJC, Vicari MR, Artoni RF, Oliveira C and Foresti F (2014) Single origin of sex chromosomes and multiple origins of B chromosomes in fish genus Characidium. PLoS One 9:e107169.

Pazian MF, Shimabukuro-Dias CK, Pansonato-Alves JC, Oliveira $\mathrm{C}$ and Foresti $\mathrm{F}$ (2013) Chromosome painting of Z and W sex chromosomes in Characidium (Characiformes, Crenuchidae). Genetica 141:1-9.

Pinheiro VSS, Carvalho NDM, Carmo EJ, Schneider CH, Feldberg E and Gross MC (2016) Karyoevolution in Potamorhina (Cope, 1878) (Ostariophysi, Curimatidae): Using repetitive DNA for the elucidation of genome organization. Zebrafish 13:118-131.

Pinkel D, Straume T and Gray JW (1986) Cytogenetic analysis using quantitative, high-sensitivity, fluorescence hybridization. Proc Natl Acad Sci USA 83:2934-2938.

Pucci MB, Barbosa P, Nogaroto V, Almeida MC, Artoni RF, Pansonato-Alves JC, Foresti F, Moreira-Filho O and Vicari MR (2014) Population differentiation and speciation in the genus Characidium (Characiformes: Crenuchidae): Effects of reproductive and chromosomal barriers. Biol J Linnean Soc 111:541-553.

Pucci MB, Barbosa P, Nogaroto V, Almeida MC, Artoni RF, Scacchetti PC, Pansonato-Alves JC, Foresti F, MoreiraFilho O and Vicari MR (2016) Chromosomal spreading of microsatellites and (TTAGGG) $)_{\mathrm{n}}$ sequences in the Characidium zebra and C. gomesi genomes (Characiformes: Crenuchidae). Cytogenet Genome Res 149:182-190.

Scacchetti PC, Utsunomia R, Pansonato-Alves JC, Silva GJC, Vicari MR, Artoni RF, Oliveira C and Foresti F (2015a) Repetitive DNA sequences and evolution of ZZ/ZW sex chromosomes in Characidium (Teleostei: Characiformes). PLoS One 10:e137231.

Scacchetti PC, Utsunomia R, Pansonato-Alves JC, Vicari MR, Artoni RF, Oliveira C and Foresti F (2015b) Chromosomal mapping of repetitive DNAs in Characidium (Teleostei, Characiformes): Genomic organization and diversification of ZW sex chromosomes. Cytogenet Genome Res 146:136143. 
Schneider CH, Gross MC, Terencio ML, Carmo EJ, Martins C and Feldberg E (2013) Evolutionary dynamics of retrotransposable elements Rex1, Rex3 and Rex6 in Neotropical cichlid genomes. BMC Evol Biol 13:152.

Sene VF, Pansonato-Alves JC, Ferreira DC, Utsunomia R, Oliveira C and Foresti F (2015) Mapping of the retrotransposable elements Rexl and Rex3 in chromosomes of Eigenmannia (Teleostei, Gymnotiformes, Sternopygidae). Cytogenet Genome Res 146:319-324.

Serrano EA, Utsunomia R, Scudeller PS, Oliveira C and Foresti F (2017) Origin of B chromosomes in Characidium alipioi (Characiformes, Crenuchidae) and its relationship with supernumerary chromosomes in other Characidium species. Comp Cytogenet 11:81-95.

Sumner AT (2003) Chromosomes: Organization and Function. Blackwell Publishing Company, London, $287 \mathrm{pp}$.

Szamalek JM, Goidts V, Chuzhanova N, Hameister H, Cooper DN and Kehrer-Sawatzki H (2005) Molecular characterisation of the pericentric inversion that distinguishes human chromosome 5 from the homologous chimpanzee chromosome. Hum Genet 117:168-176.

Tollis M and Boissinot S (2012) The evolutionary dynamics of transposable elements in eukaryote genomes. Genome Dyn 7:68-91.

Úbeda-Manzanaro M, Merlo MA, Palazón JL, Cross I, Sarasquete $\mathrm{C}$ and Rebordinos L (2010) Chromosomal mapping of the major and minor ribosomal genes, (GATA) ${ }_{n}$ and U2 snRNA gene by double-colour FISH in species of the Batrachoididae family. Genetica 138:787-794.

Utsunomia R, Scacchetti PC, Hermida M, Fernández-Cebrián R, Taboada X, Fernández C, Bekaert M, Mendes NJ, Robledo D, Mank JE et al. (2017) Evolution and conservation of Characidium sex chromosomes. Heredity 119:237-244.
Vicari MR, Artoni RF, Moreira-Filho O and Bertollo LAC (2008) Diversification of a ZZ/ZW sex chromosome system in Characidium fish (Crenuchidae, Characiformes). Genetica 134:311-317.

Wells RD (2007) Non-B DNA conformations, mutagenesis and disease. Trends Biochem Sci 32:271-278.

Wicker T, Sabot F, Hua-Van A, Bennetzen JL, Capy P, Chalhoub B, Flavell A, Leroy P, Morgante M, Panaud O et al. (2007) A unified classification system for eukaryotic transposable elements. Nat Rev Genet 8:973-982.

Yano CF, Poltronieri J, Bertollo LAC, Artoni RF, Liehr T and de Bello Cioffi M (2014) Chromosomal mapping of repetitive DNAs in Triportheus trifurcatus (Characidae, Characiformes): insights into the differentiation of the $\mathrm{Z}$ and W chromosomes. PLoS One 9:e90946.

\section{Internet Resources}

Girinst, www.girinst.org (October 4, 2016)

NCBI, http://www.ncbi.nlm.nih.gov/blast (October 7, 2016)

\section{Supplementary material}

The following online material is available for this article: Table S1 - PCR reaction mixture for the synthesis of probes used in this work.

Table S2 - Partial sequences isolated from the Characidium species/population genome.

Associate Editor: Yatio Yonenaga-Yassuda

License information: This is an open-access article distributed under the terms of the Creative Commons Attribution License (type CC-BY), which permits unrestricted use, distribution and reproduction in any medium, provided the original article is properly cited. 